Article

\title{
Energy Commitment for a Power System Supplied by Multiple Energy Carriers System using Following Optimization Algorithm
}

\author{
Mohammad Dehghani ${ }^{1}{ }^{(\mathbb{D}}$, Mohammad Mardaneh $\left.^{1}{ }^{(}\right)$, Om Parkash Malik ${ }^{2}{ }^{(1)}$, \\ Josep M. Guerrero $^{3}{ }^{(D)}$, Ruben Morales-Menendez ${ }^{4} \mathbb{D}$, Ricardo A. Ramirez-Mendoza ${ }^{4, *}$, \\ José Matas $^{5}$ (D) and Abdullah Abusorrah ${ }^{6}$ (D) \\ 1 Department of Electrical and Electronics Engineering, Shiraz University of Technology, \\ Shiraz 71557-13876, Iran; m.dehghani@sutech.ac.ir (M.D.); mardaneh@sutech.ac.ir (M.M.) \\ 2 Department of Electrical and Computer Engineering, University of Calgary, Calgary, AB T2N 1N4, Canada; \\ maliko@ucalgary.ca \\ 3 CROM Center for Research on Microgrids, Department of Energy Technology, Aalborg University, \\ 9220 Aalborg, Denmark; joz@et.aau.dk \\ 4 School of Engineering and Sciences, Tecnologico de Monterrey, Monterrey 64849, Mexico; rmm@tec.mx \\ 5 Electric Engineering Department, Polytechnic University of Catalonia (EEBE-UPC), 08019 Barcelona, Spain; \\ jose.matas@upc.edu \\ 6 Center of Research Excellence in Renewable Energy and Power Systems, Department of Electrical and \\ Computer Engineering, Faculty of Engineering, K. A. CARE Energy Research and Innovation Center, King \\ Abdulaziz University, Jeddah 21589, Saudi Arabia; aabusorrah@kau.edu.sa \\ * Correspondence: ricardo.ramirez@tec.mx; Tel.: +52-81-2001-5597
}

Received: 29 July 2020; Accepted: 12 August 2020; Published: 24 August 2020

check for updates

\begin{abstract}
In today's world, the development and continuation of life require energy. Supplying this energy demand requires careful and scientific planning of the energy provided by a variety of products, such as oil, gas, coal, electricity, etc. A new study on the operation of energy carriers called Energy Commitment (EC) is proposed. The purpose of the EC is to set a pattern for the use of energy carriers to supply energy demand, considering technical and economic constraints. EC is a constrained optimization problem that can be solved by using optimization methods. This study suggests the Following Optimization Algorithm (FOA) to solve the EC problem to achieve technical and economic benefits. Minimizing energy supply costs for the total study period is considered as an objective function. The FOA simulates social relationships among the community members who try to improve their community by following each other. Simulation is carried out on a 10-unit energy system supplied by various types of energy carriers that includes transportation, agriculture, industrial, residential, commercial, and public sectors. The results show that the optimal energy supply for a grid with 0.15447 Millions of Barrels of Oil Equivalent (MBOE) of energy demand costs 9.0922 millions dollar for a 24-h study period. However, if the energy supply is not optimal, the costs of operating energy carriers will increase and move away from the optimal economic situation. The economic distribution of electrical demand between 10 power plants and the amount of production units per hour of the study period is determined. The EC outputs are presented, which include an appropriate pattern of energy carrier utilization, energy demand supply costs, appropriate combination of units, and power plant production. The behavior and process of achieving the answer in the convergence curve for the implementation of FOA on EC indicates the exploration and exploitation capacity of FOA. Based on the simulated results, EC provides more information than Unit Commitment (UC) and analyzes the network more efficiently and deeply.
\end{abstract}


Keywords: energy; energy commitment; energy carrier; multi-carrier energy; following optimization algorithm

\section{Introduction}

An energy carrier is a substance-for example, fuel, or sometimes a phenomenon (energy system) - that contains energy, which can be later converted to other forms, such as mechanical work or heat, or operate chemical or physical processes. Today's societies use several energy carriers in the industry, service, residential, and transportation sectors. Among the various energy carriers, oil is of paramount importance, since its price has a considerable effect on economic growth. Besides, neither oil nor any of the fossil fuels such as coal and natural gas have endless sources. The growing demand on the one hand and declining fossil resources, on the other hand, necessitate full consideration for the operation of energy. Therefore, the operation of energy carriers to supply the energy demand, called the Energy Commitment (EC) problem, is studied, in particular from the perspective of an electric power system.

Unit Commitment (UC) is a significant study carried out in the operation of the electricity grid. An essential criterion in UC is the supply of power demand with the least fuel cost and optimal combination of different power plants [1]. It forms the basis of energy carrier commitment.

The UC issue has been of great interest to researchers as evident from the following representative literature. In [2], uncertainty in the production of virtual power plants is investigated, and transmission line constraints in solving the UC problem for large-scale networks are studied in [3]. The UC problem in the presence of Flexible AC Transmission System (FACTS) devices and energy storage devices is investigated in [4]. To solve the UC problem, a novel annual analysis is proposed for the thermal power generator and pumped storages under a massive introduction of renewable energy sources [5]. Ref. [6], the authors proposed the implementation of the UC in the presence of energy storage systems and its optimal size for a region in northern Chile. Solving the UC problem in the presence of wind, nuclear, and thermal power plants has been studied by considering the security constraints of the transmission line and the influence of wind power uncertainty on the spinning reserve capacity of the system in China [7]. A new method based on the Particle Swarm Optimization (PSO) algorithm, [8], and the solution of the UC problem using genetic algorithm was proposed in [9]. Other algorithms, such as the Gray Wolf Optimizer (GWO) [10], Whale Optimization Algorithm (WOA) [11], simulated annealing [12], and shuffled frog-leaping algorithm [13] have also been suggested to find the solution to the UC problem.

In recent years, Multi-Carrier Energy (MCE) systems that improve energy efficiency and reliability have received much attention. Each of the gas, electrical, and heat networks consists of energy sources, several loads, and a set of transmission lines or pipes that supply energy demand through the resources of the system. The flow value of the supply lines of each of these grids can be calculated mathematically by the quantities of those lines [14].

A mathematical model for intelligent loads participation in load response programs in an MCE system management is proposed, [15]. In this model, the optimal operation is performed using an energy storage system. The effects of load response programs on the efficiency and operating costs of MCE systems in the presence and absence of wind energy and energy storage are evaluated and analyzed in [16]. The teaching and learning-based optimization algorithm is applied to optimize the operation of MCE systems in [17].

In general, an Energy Hub (EH) is an interface between the production, consumption, and transmission of different forms of energy. EHs are connected to electric power grids and perform energy conversion operations from one state to another or improve the quality of energy delivered to the load. Thus, the inputs of an EH consist of different forms of energy, and its outputs are system 
loads. The purpose of the EH is to provide the required energy for load demand through its input and internal equipment [18].

The concept of EH has been introduced in various residential, commercial, and other applications. In this regard, economy and energy savings in a hospital have been studied [19], and linear integer programming is presented to improve the performance of an electric micro-grid in the presence of cooling, thermal, and electrical loads [20]. The optimal operation of a residential house as an EH using the PSO algorithm is proposed in [21]. The optimal operation of an EH has been studied considering the energy storage systems in [22]. The EH has also been proposed for economic and reliability purposes in [23] with the aim of proper selection of the internal EH equipment. Furthermore, the energy management of smart hubs is discussed in [24].

As mentioned in the previous subsections, in UC, the goal is to determine the appropriate pattern of power plant production to supply the electrical demand. In an MCE system, gas, electrical, and heat networks are examined, and the purpose of the $\mathrm{EH}$ is to supply the required energy demand through its input and internal equipment. Although very valuable studies have been conducted by researchers in the operation of power systems, the operation of an integrated grid called the energy grid and determining the appropriate pattern of use of energy carriers to supply energy demand in this network has been less studied. Therefore, a new study named the Energy Commitment (EC) problem that determines a suitable pattern of energy carriers utilization to supply the energy demand in particular from the perspective of an electric power system is proposed. In the proposed EC study, more details of the network such as the simulation of oil refining and the impact of the imports and exports of energy carriers are considered.

The EC problem in a multi-carrier energy system is proposed to be studied using the Following Optimization Algorithm (FOA). Therefore, the optimal operation of energy carriers can be obtained. The proposed study aims to realize the following:

- Mathematical modeling and formulation for an EC problem.

- Objective function is considered as minimizing energy supply costs for the total study period.

- The FOA is used to solve the EC problem, which is a constrained optimization problem.

- Study the technical aspect of supply energy demand in various sections (with different types of energy carriers).

- Applying the proposed study to a standard energy grid that includes different sectors of energy consumption (transportation, agriculture, industrial, residential, commercial, and public).

- Studying the simulation of refinery and oil-refining process.

- Studying the impact of import and export of energy carriers on EC.

- Determining the appropriate pattern for the use of energy carriers to supply energy demand, considering technical and economic constraints.

- Increasing the awareness of the importance of an EC study to enhance the operation of energy systems.

The introduction and background of the topic are presented in Section 1. The problem definition and problem formulation are described, respectively, in Sections 2 and 3. Application of the proposed study is investigated and discussed in Section 4, while the conclusions are presented in Section 5.

\section{Problem Definition}

\subsection{Energy Commitment}

Researchers have provided valuable studies on energy and energy management [25-29]. A significant issue in energy studies is the operation of energy carriers. The primary energy carriers are those that are directly extracted from natural sources such as crude oil, hard coal, and natural gas. All carriers of energy, not primary but produced from primary energy, are called secondary energy 
carriers [30]. Table 1 shows an overview of renewable versus non-renewable energy and primary versus secondary energy.

Table 1. Terminology for Energy Commodities [30].

\begin{tabular}{|c|c|c|c|c|}
\hline & \multicolumn{2}{|c|}{ Primary } & Secondary & \\
\hline & \multicolumn{3}{|c|}{ Combustible } & \\
\hline Non-renewable & nuclear & $\begin{array}{ll}\text { - } & \text { Coals } \\
\text { - } & \text { Crude oil } \\
\text { - } & \text { Liquid Gas } \\
\text { - } & \text { Natural gas } \\
\text { - } & \text { Oil shale }\end{array}$ & $\begin{array}{ll}\text { - } & \text { Petroleum products } \\
\text { - } & \text { Manufactured } \\
\text { solid fuels } \\
\text { - } & \text { Gases }\end{array}$ & \multirow[t]{2}{*}{ Heat and electricity } \\
\hline Renewable & $\begin{array}{l}\text { heat and non-thermal } \\
\text { electricity }\end{array}$ & - Biofuels & $\begin{array}{l}\text { Any fuels derived } \\
\text { from renewables }\end{array}$ & \\
\hline
\end{tabular}

Researchers over time have conducted wide research into the operation of power systems and power supply to consumers. In the unit commitment study, the on or off status of the units and the optimal production of each unit are determined for a specific period of study based on the predicted electric demand. Although resolving the UC provides valuable information, dependencies between energy carriers are not considered.

Therefore, the following can be mentioned:

- The UC focuses solely on the study of the electrical grid and the supply of electrical demand.

- In the UC, only the forecast of electricity demand is available.

- Independent optimization of energy networks does not necessarily lead to the optimization of the entire energy network.

- In the UC, possible substitutions between energy carriers are not considered.

The study of EC is introduced with the attitude of operation of energy carriers in an integrated energy network, considering the possibility of possible substitutions between energy carriers. In the proposed EC study, instead of forecasting electricity consumption, forecasting energy demand for other energy carriers is also available, and based on this, the optimal operation of energy carriers is presented simultaneously.

EC determines the most appropriate pattern of using energy carriers wherein first technical problems and then economic issues are adequately addressed. If the energy carriers are used according to the peak demand, it will cost a lot. In fact, energy carriers should be optimally utilized, as managing energy resources properly can save a considerable amount of money. In the EC issue, first, the energy demand (actually the energy demand curve) must be determined. This energy demand curve, similar to the UC problem, can be a 24-h curve. In the UC problem, for every hour of the study, there is an electricity demand that must be met by the appropriate combination of units. However, in the EC, for every hour of the study, there is an energy demand of different types, including electricity, gas, car fuel, aircraft fuel, etc., which must be met using the appropriate combination of energy carriers.

\subsection{Energy Grid}

The EC study should be done in a proper space called the energy grid. The various sectors of the proposed energy grid are transportation, agriculture, industrial, residential, commercial, and public sectors. 
In the energy grid, the energy demand is calculated as the sum of the demand in the various subdivisions of the grid using (1):

$$
E C_{f}=E C_{1}+E C_{2}+\ldots+E C_{N}=\sum_{i=1}^{N} E C_{i}
$$

where $E C_{f}$ is the total energy demand, $E C_{i}$ is the energy demand of the $i$-th sector of the grid, and $N$ is the number of different sectors of the energy grid.

The primary constraint on the EC problem is to supply the total energy demand. The energy consumption in different parts is (2):

$$
E_{1}=\left[E C_{1} E C_{2} \ldots E C_{i} \ldots E C_{N}\right]^{T}
$$

where $E_{1}$ is the energy demand matrix in the various energy sectors. This energy demand can include a variety of energy carriers such as natural gas, electricity, coal, etc. For the energy grid proposed, the energy demand is considered to be as below:

$$
E_{1}=\left[\begin{array}{ll}
E C_{1} & \text { total energy demand in residential, commercial, and public sector } \\
E C_{2} & \text { total energy demand in industrial sector } \\
E C_{3} & \text { total energy demand in transportation sector } \\
E C_{4} & \text { total energy demand in agriculture sector } \\
E C_{5} & \text { total energy demand in other sector } \\
E C_{6} & \text { total energy demand in non - energy sector }
\end{array}\right]
$$

\section{Problem Formulation}

Energy network matrix modeling is presented. This modeling is performed in several steps, from the lowest energy level (final energy consumption) to the highest energy level (primary energy carriers).

Final energy consumption based on different energy carriers is specified as:

$$
E_{2}=T_{1,2} \times E_{1}
$$

where $E_{2}$ is the final energy consumption based on different energy carriers and $T_{1,2}$ is the transform matrix of different sectors to different energy carriers. The values of $T_{1,2}$ are determined based on the simulation of experimental and practical data.

Energy loss is modeled using (4).

$$
E_{3}=T_{2,3} \times E_{2}
$$

where $E_{3}$ is the final energy consumption based on different energy carriers considering losses and $T_{2,3}$ is the efficiency matrix. The values of $T_{2,3}$ are determined based on the simulation of experimental and practical data.

At this stage, the electrical energy is proportioned to the energy carriers. In fact, at this point, the UC problem must be resolved. The electrical energy of different power plants is determined as shown in (5):

$$
E_{u}=T_{u} \times E_{e}
$$

where $E_{u}$ is the electrical energy of different power plants, $T_{u}$ is the separation matrix of electricity generated by various power plants that is calculated based on solving UC, and $E_{e}$ is the total electricity demand.

Input fuel for different power plants is determined by (6):

$$
E_{e_{1}}=T_{u, f} \times E_{u}
$$


where $E_{e_{1}}$ is the input fuel for different power plants and $T_{u, f}$ is the power plant efficiency matrix.

The source energy carrier for electricity generation is determined using (7).

$$
E_{e_{2}}=T_{f, c} \times E_{e_{1}}
$$

where $E_{e_{2}}$ is the source energy carrier for electricity generation and $T_{f, c}$ is the conversion matrix of input fuel to energy carriers.

After the calculation of electrical energy, the final energy consumption is calculated using (8).

$$
E_{4}=E_{3}+E_{e_{2}}-E_{e}
$$

where $E_{4}$ is the final energy consumption after converting electrical energy to input carriers to units.

At this stage, the process of refining crude oil is simulated using (9).

$$
E_{p_{1}}=T_{p} \times E_{p}
$$

where $E_{p_{1}}$ represents the energy carriers produced by refining, $T_{p}$ is the separation matrix of products created from refining crude oil, and $E_{p}$ is the maximum capacity of refineries.

After simulation of the refining crude oil process, the final energy consumption is calculated using (10).

$$
E_{5}=E_{4}+E_{p}-E_{p_{1}}
$$

where $E_{5}$ is the final energy consumption after refining crude oil. Actually, $E_{5}$ determines the energy carriers that supply the energy demand.

Import and export of energy carriers are determined by (11):

$$
E_{6}=E_{5}-P
$$

where $P$ is the domestic production of energy carriers, and $E_{6}$ is the import and/or export of energy carriers. In $E_{6}$, the positive sign means import and negative sign means export of energy carriers.

\section{Simulation Studies}

Optimization algorithms have the ability to solve complex problems. In this regard, various optimization algorithms have been introduced by researchers [31-40] and have been applied by scientists in various fields such as energy [41], protection [42], electrical engineering [43-46], and energy carriers $[47,48]$ to achieve the optimal solution. The EC problem is simulated on an MCE system, and the Following Optimization Algorithm (FOA) [49] as an optimization method is used in the simulations to find the best solution of the EC problem.

\subsection{Case Study}

The EC problem is tested on an energy grid with 10 generating plants. The final energy consumption for a 24-hour period is presented in Table A8. The transform matrix of different sectors to different energy carriers $\left(T_{1,2}\right)$ is specified in Table A9. The energy unit used in this article is Millions of Barrels of Oil Equivalent (MBOE).

\subsection{Simulation Studies and Discussion}

\subsubsection{Electrical Energy}

A network with 10 electric power plants is used. Information on these plants is provided in Appendix A. According to Algorithm 1, at each hour of the study, the economic distribution of electrical energy is solved for all possible combinations of power plants. 


\subsubsection{Following Optimization Algorithm (FOA)}

In FOA, [49], which is a swarm-based algorithm, search factors are indeed members of the community that try to improve the community by 'following' each other. (12) to (14) are the main equations of the FOA.

$$
\begin{gathered}
x_{i}^{d}=(1-f r) x_{i, 0}^{d}+f r x_{\text {leader }}^{d} \\
f=1-\exp \left(\frac{-t^{1.5}}{T}\right) \\
x_{\text {leader }}= \begin{cases}\text { for minimization problem }: \text { location of } \min \left(\text { fit }_{j}\right) & j \in\{1: N\} \\
\text { for maximization problem }: \text { location of } \max \left(\text { fit }_{j}\right) & j \in\{1: N\}\end{cases}
\end{gathered}
$$

In the above equations, $x_{i, 0}^{d}$ refers to the initial balance point along with the $d$ dimension of member $i$, and $r$ represents a random number with a uniform distribution within the [0-1] span used to preserve the search random state. $x_{\text {leader }}$ shows the values of the problem variables for the best member of the community, which is named the leader. Moreover, $x_{\text {leader }}^{d}$ is the $d$-th dimension of the position of the mentioned leader. Symbol ' $f$ ' represents the 'following' co-efficient, $t$ is the iteration count, $T$ is the maximum number of iterations, and fit is the community fitness vector.

\subsubsection{Objective Function and Constraints}

The objective function for the EC problem is defined in (15). The constraints on start-up costs and production range of units are specified in (16) and (18), respectively.

$$
\begin{gathered}
F_{\text {objective }}=\min \left\{\sum_{t=1}^{T}\left[\sum_{i=1}^{N_{c}} \text { carrier }_{i}^{t} \times \text { price }_{i}+\sum_{i=1}^{N_{g}} S C_{i}^{t}+\sum_{i=1}^{N_{g}} C_{i} u_{i}^{t}\right]\right\} \\
S C_{i}^{t}=\left\{\begin{array}{c}
S C_{i}, u_{i}^{t}>u_{i}^{t-1} \\
0, \text { else }
\end{array}\right. \\
P_{g_{i}}^{\min } \leq P_{g_{i}} \leq P_{g_{i}}^{\max } \\
\sum_{i=1}^{N_{g}} P_{g_{i}}^{t}=\text { load }^{t}
\end{gathered}
$$

where $T$ is the study period, $N_{c}$ is the number of various carriers, carriert in the need for the $i$-th carrier at the $t$-th hour, and price $i$ is its price, $N_{g}$ is the number of units, $S C_{i}^{t}$ is the start-up cost for the $i$-th unit in the $t$-th hour, $C_{i}$ is the fixed cost for the $\mathrm{i}$-th unit and $u_{i}^{t}$ is the status (on or off) of it in the $t$-th hour, $P_{g_{i}}$ is the production of the $i$-th unit, and load is the electricity demand in the $t$-th hour.

The EC problem solution steps are shown in Algorithm 1. The flowchart of the EC solution method using the FOA algorithm is also shown in Figure 1. 


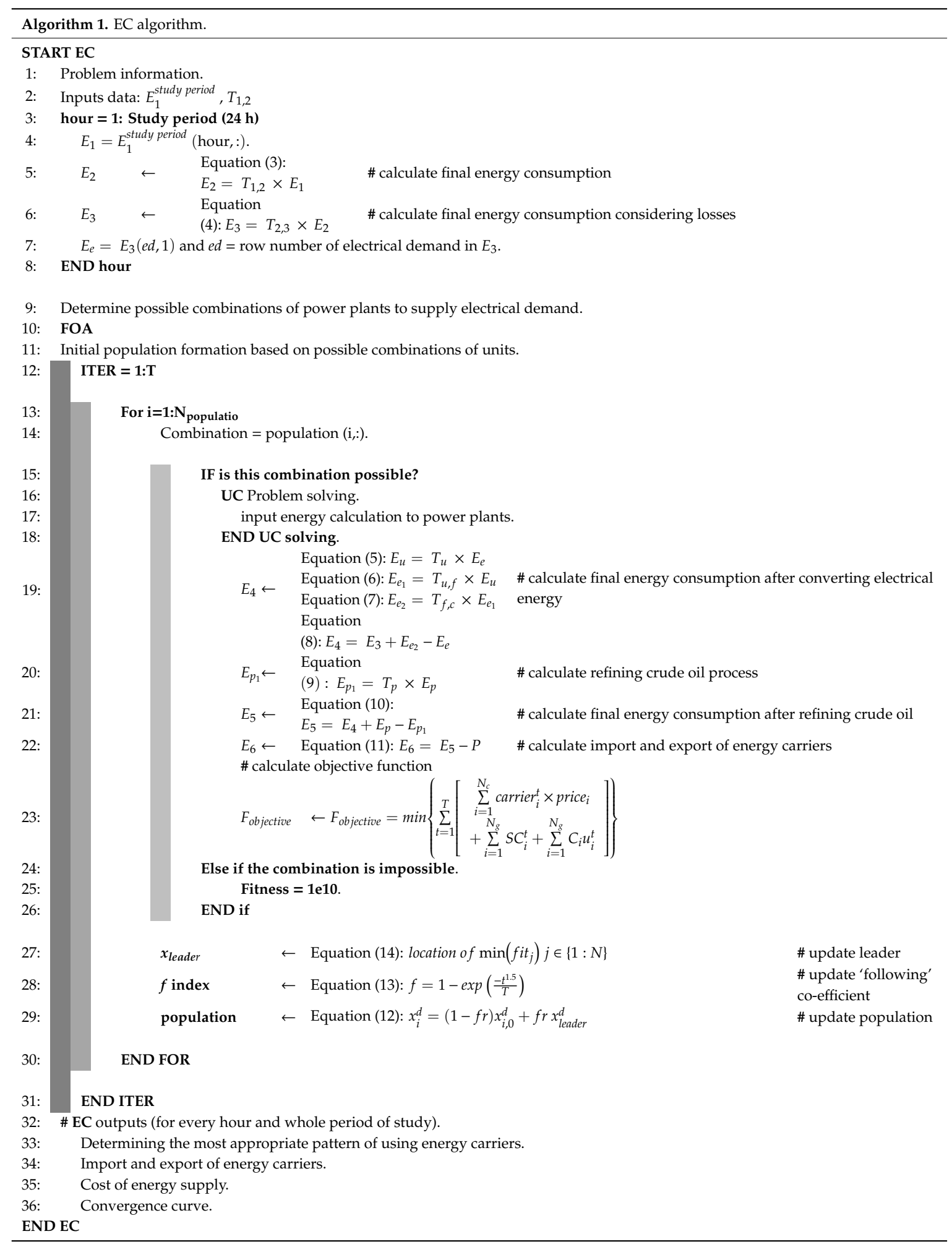




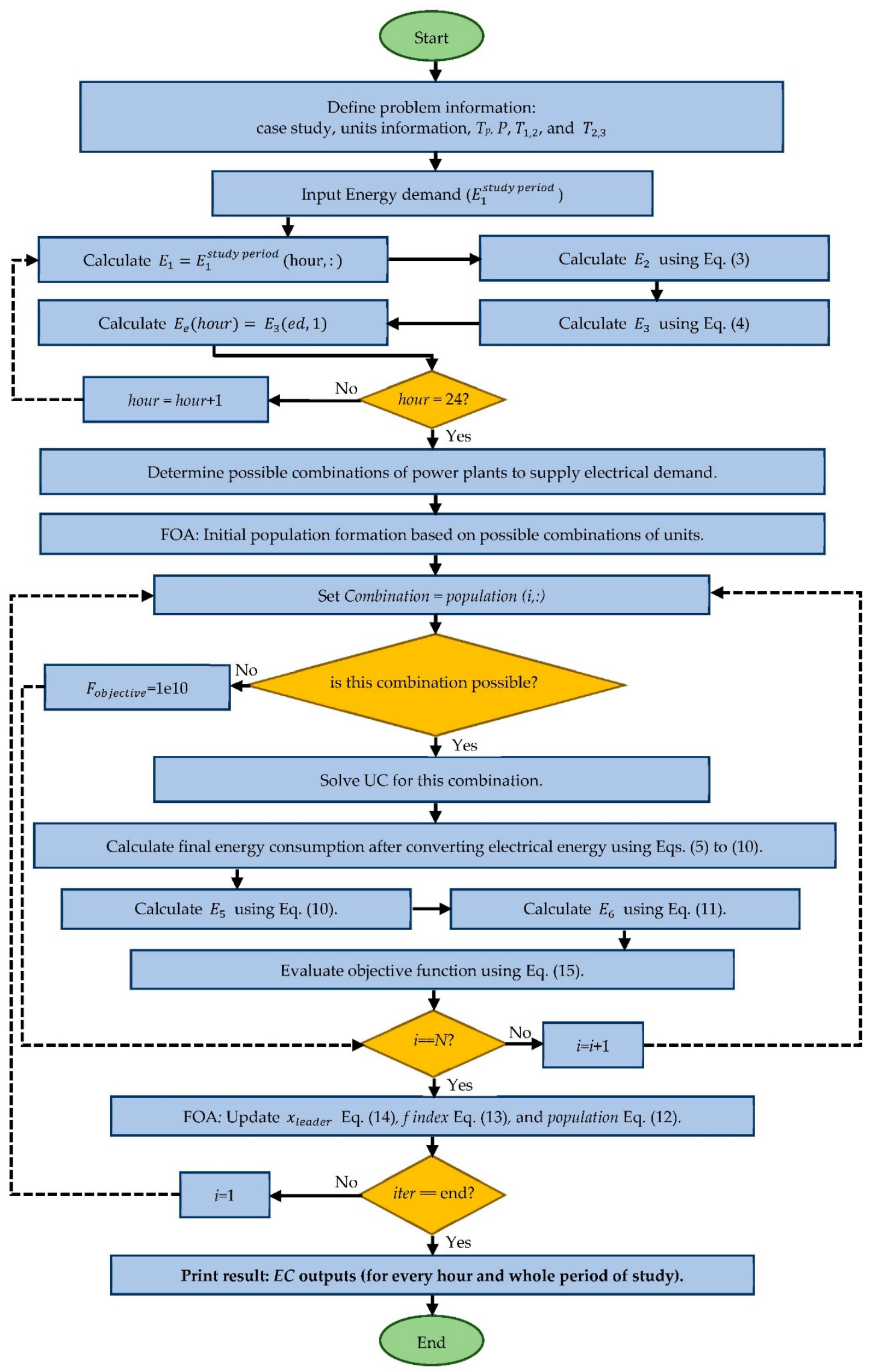

Figure 1. Energy Commitment (EC) flowchart. 


\subsubsection{Results and Finding}

The proposed EC operation is simulated on the mentioned energy grid with 10 power plants and energy demand in different sectors of transportation, agriculture, industrial, residential, commercial, and public. The EC problem is coded in MATLAB and executed on a system with a quad-core $3.3 \mathrm{GHz}$ processor and $8 \mathrm{~GB}$ of RAM.

Table 2 presents one of the most important outputs of EC i.e., determining the appropriate combination of power plant units to meet the electricity demand. For each hour of operation, different combinations of power plant units are available to meet the electricity demand. However, a combination of units must be chosen that is also economical. According to Table 2, the appropriate combination for the entire 24-h study period is the combination: $(2,2,3,3,4,5,6,7,8,9,10,10,9,6,5,5,5,5,7,7,7,3,3,3)$. The value of the objective function based on this combination is 9.0922 million dollars.

Table 2. The appropriate combination of units and total cost for energy supply.

\begin{tabular}{lllllllllllllllllllllllllllllllllll}
\hline Hour & 1 & 2 & 3 & 4 & 5 & 6 & 7 & 8 & 9 & 10 & 11 & 12 & 13 & 14 & 15 & 16 & 17 & 18 & 19 & 20 & 21 & 22 & 23 & 24 & $\begin{array}{c}\text { Cost } \\
\text { Dillions } \\
\text { Dollar) }\end{array}$ \\
\hline Combination & 2 & 2 & 3 & 3 & 4 & 5 & 6 & 7 & 8 & 9 & 10 & 10 & 9 & 6 & 5 & 5 & 5 & 5 & 7 & 7 & 7 & 3 & 3 & 3 & 9.0922 \\
\hline
\end{tabular}

Table 3 presents the need for energy carriers to meet the total energy demand as another important output of EC. In this table, for each hour of operation, the optimal amount of energy carriers is determined, which also includes the losses of the energy network. For example, in the network studied, 104.1298 BOE of liquid gas, 520.0702 BOE of fuel oil, 634.0488 BOE of gas oil, 235.3108 BOE of kerosene, 602.9689 BOE of gasoline, 32.33808 BOE of plane fuel, 2639.622 BOE of natural gas, 16.21232 BOE of coke gas, and $35.83295 \mathrm{BOE}$ coal are needed to meet the energy demand in the first hour of operation.

Table 3. The need for energy carriers (BOE) to supply the energy demand. BOE: Barrels of Oil Equivalent.

\begin{tabular}{|c|c|c|c|c|c|c|c|c|}
\hline Hour & 1 & 2 & 3 & 4 & 5 & 6 & 7 & 8 \\
\hline Liquid gas & 104.1298 & 111.5676 & 126.4433 & 141.3189 & 148.7568 & 163.6325 & 171.0703 & 178.5081 \\
\hline Fuel oil & 520.0702 & 558.1365 & 625.2257 & 691.7656 & 717.0365 & 755.9679 & 786.1914 & 826.9545 \\
\hline Gas oil & 634.0488 & 679.3489 & 772.0559 & 864.8909 & 913.3675 & 1020.223 & 1067.949 & 1113.281 \\
\hline Kerosene & 235.3108 & 252.1187 & 285.7345 & 319.3504 & 336.1583 & 369.7741 & 386.582 & 403.3899 \\
\hline Gasoline & 602.9689 & 646.0381 & 732.1765 & 818.3149 & 861.3841 & 947.5225 & 990.5917 & 1033.661 \\
\hline Plane fuel & 32.33808 & 34.64795 & 39.26767 & 43.8874 & 46.19726 & 50.81699 & 53.12685 & 55.43671 \\
\hline Natural gas & 2639.622 & 2830.853 & 3211.644 & 3592.334 & 3783.39 & 4181.017 & 4377.497 & 4576.617 \\
\hline Coke gas & 16.21232 & 17.37034 & 19.68639 & 22.00243 & 23.16046 & 25.4765 & 26.63452 & 27.79255 \\
\hline Coal & 35.83295 & 38.39245 & 43.51144 & 48.63043 & 51.18993 & 56.30892 & 58.86842 & 61.42791 \\
\hline hour & 9 & 10 & 11 & 12 & 13 & 14 & 15 & 16 \\
\hline Liquid gas & 193.3838 & 215.6973 & 230.573 & 246.1925 & 223.1352 & 208.2595 & 178.5081 & 156.1946 \\
\hline Fuel oil & 881.7413 & 928.0273 & 1002.576 & 1044.985 & 966.8135 & 894.5986 & 832.8839 & 732.4652 \\
\hline Gas oil & 1224.697 & 1402.697 & 1497.324 & 1611.015 & 1448.653 & 1355.62 & 1113.497 & 971.3697 \\
\hline Kerosene & 437.0058 & 487.4295 & 521.0453 & 556.342 & 504.2374 & 470.6216 & 403.3899 & 352.9662 \\
\hline Gasoline & 1119.799 & 1249.007 & 1335.145 & 1425.591 & 1292.076 & 1205.938 & 1033.661 & 904.4533 \\
\hline Plane fuel & 60.05644 & 66.98603 & 71.60575 & 76.45647 & 69.29589 & 64.67617 & 55.43671 & 48.50712 \\
\hline Natural gas & 5002.489 & 5643.05 & 6045.205 & 6465.625 & 5843.64 & 5444.886 & 4579.159 & 3990.681 \\
\hline Coke gas & 30.10859 & 33.58266 & 35.89871 & 38.33055 & 34.74068 & 32.42464 & 27.79255 & 24.31848 \\
\hline Coal & 66.5469 & 74.22539 & 79.34439 & 84.71933 & 76.78489 & 71.6659 & 61.42791 & 53.74942 \\
\hline hour & 17 & 18 & 19 & 20 & 21 & 22 & 23 & 24 \\
\hline Liquid gas & 148.7568 & 178.5081 & 208.2595 & 193.3838 & 163.6325 & 133.8811 & 126.4433 & 119.0054 \\
\hline Fuel oil & 717.0365 & 832.8839 & 907.5986 & 876.7413 & 760.8939 & 663.2921 & 625.2257 & 587.1594 \\
\hline Gas oil & 920.7956 & 1113.497 & 1352.626 & 1228.716 & 1019.635 & 817.3559 & 772.0559 & 726.7558 \\
\hline Kerosene & 336.1583 & 403.3899 & 470.6216 & 437.0058 & 369.7741 & 302.5425 & 285.7345 & 268.9266 \\
\hline Gasoline & 861.3841 & 1033.661 & 1205.938 & 1119.799 & 947.5225 & 775.2457 & 732.1765 & 689.1073 \\
\hline Plane fuel & 46.19726 & 55.43671 & 64.67617 & 60.05644 & 50.81699 & 41.57754 & 39.26767 & 36.95781 \\
\hline Natural gas & 3803.633 & 4579.159 & 5447.676 & 5008.352 & 4188.186 & 3402.875 & 3211.644 & 3020.413 \\
\hline Coke gas & 23.16046 & 27.79255 & 32.42464 & 30.10859 & 25.4765 & 20.84441 & 19.68639 & 18.52836 \\
\hline Coal & 51.18993 & 61.42791 & 71.6659 & 66.5469 & 56.30892 & 46.07093 & 43.51144 & 40.95194 \\
\hline
\end{tabular}


Moreover, according to domestic production, the results of the import and export of energy carriers are shown in Table 4. According to this table, petroleum (171,897), fuel oil (8857.3), gas oil (1952.09), kerosene (127.814), and coke gas (39.72) are in the export section, and liquid gas (1055.61), gasoline (8777.53), plane fuel (1263.726), natural gas (2964.27), and coal (390.38) are in the import section.

Table 4. Import and export of carriers (BOE).

\begin{tabular}{ccc}
\hline Hour & Import & Export \\
\hline Petroleum & 0 & 171,897 \\
Liquid gas & 1055.61 & 0 \\
Fuel oil & 0 & 8857.3 \\
Gas oil & 0 & 1952.09 \\
Kerosene & 0 & 127.814 \\
Gasoline & 8777.53 & 0 \\
Plane fuel & 1263.726 & 0 \\
Natural gas & 2964.269 & 0 \\
Coke gas & 0 & 39.7234 \\
Coal & 390.384 & 0 \\
\hline
\end{tabular}

Table 5 presents the optimal combination and amount of production of power plant units for each hour of the study period. In fact, this table contains information about the two important outputs of the energy commitment i.e., ED and UC. ED is to determine the most appropriate production pattern of units according to economic and technical constraints.According to this table, it is clear that the mentioned energy network has the peak of energy demand in the 12th hour of operation. In addition, at the 11th hour of operation, the amount of electricity demand is such that all units are turned on to supply it.

Table 5. Unit Commitment (UC) result (MW).

\begin{tabular}{ccccccccccc}
\hline Unit 1 & Unit 2 & Unit 3 & Hour & Unit $\mathbf{4}$ & Unit $\mathbf{5}$ & Unit $\mathbf{6}$ & Unit 7 & Unit $\mathbf{8}$ & Unit 9 & Unit 10 \\
\hline 1 & 455 & 245.8952 & 0 & 0 & 0 & 0 & 0 & 0 & 0 & 0 \\
2 & 455 & 295.9591 & 0 & 0 & 0 & 0 & 0 & 0 & 0 & 0 \\
3 & 455 & 376.087 & 20 & 0 & 0 & 0 & 0 & 0 & 0 & 0 \\
4 & 455 & 455 & 41.21486 & 0 & 0 & 0 & 0 & 0 & 0 & 0 \\
5 & 455 & 455 & 71.2788 & 20 & 0 & 0 & 0 & 0 & 0 & 0 \\
6 & 455 & 455 & 130 & 36.40668 & 25 & 0 & 0 & 0 & 0 & 0 \\
7 & 455 & 455 & 130 & 66.47061 & 25 & 20 & 0 & 0 & 0 & 0 \\
8 & 455 & 455 & 130 & 91.53455 & 25 & 20 & 25 & 0 & 0 & 0 \\
9 & 455 & 455 & 130 & 130 & 76.66243 & 20 & 25 & 10 & 0 & 0 \\
10 & 455 & 455 & 130 & 130 & 162 & 74.85425 & 25 & 10 & 10 & 0 \\
11 & 455 & 455 & 130 & 130 & 162 & 80 & 85 & 34.98213 & 10 & 10 \\
12 & 455 & 455 & 130 & 130 & 162 & 80 & 85 & 55 & 55 & 50.11641 \\
13 & 455 & 455 & 130 & 130 & 162 & 80 & 69.91819 & 10 & 10 & 0 \\
14 & 455 & 455 & 130 & 130 & 162 & 69.79031 & 0 & 0 & 0 & 0 \\
15 & 455 & 455 & 130 & 130 & 31.53455 & 0 & 0 & 0 & 0 & 0 \\
16 & 455 & 455 & 96.34274 & 20 & 25 & 0 & 0 & 0 & 0 & 0 \\
17 & 455 & 455 & 46.2788 & 20 & 25 & 0 & 0 & 0 & 0 & 0 \\
18 & 455 & 455 & 130 & 130 & 31.53455 & 0 & 0 & 0 & 0 & 0 \\
19 & 455 & 455 & 130 & 130 & 162 & 44.79031 & 25 & 0 & 0 & 0 \\
20 & 455 & 455 & 130 & 130 & 86.66243 & 20 & 25 & 0 & 0 & 0 \\
21 & 455 & 455 & 101.4067 & 20 & 25 & 20 & 25 & 0 & 0 & 0 \\
22 & 455 & 426.1509 & 20 & 0 & 0 & 0 & 0 & 0 & 0 & 0 \\
23 & 455 & 376.087 & 20 & 0 & 0 & 0 & 0 & 0 & 0 & 0 \\
24 & 455 & 326.023 & 20 & 0 & 0 & 0 & 0 & 0 & 0 & 0 \\
\hline
\end{tabular}

The convergence curve of the performance of FOA in solving the EC problem is shown in Figure 2. This curve is plotted based on the best solution obtained until each iteration in terms of algorithm 
iteration. As shown in this figure, FOA converged in iteration number 115 and provided the optimal solution of 9.0922 million dollars.

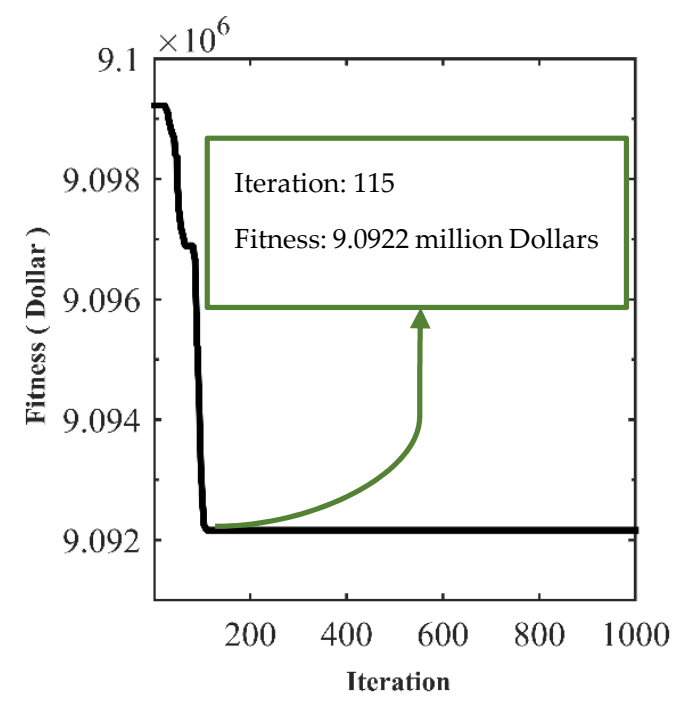

Figure 2. Convergence curve of Following Optimization Algorithm (FOA).

Based on the outputs presented from the implementation of the EC, as well as the mentioned topics, the following findings are identified.

- EC is a constrained optimization problem that can be solved using various methods, especially optimization algorithms.

- The goal in EC is determination of the most appropriate pattern of using energy carriers to supply energy demand, wherein first technical problems and then economic issues are adequately addressed.

- In the EC study, various sectors of energy consumption including transportation, agriculture, industrial, residential, commercial, and public sectors are considered.

- EC is a more accurate and in-depth study than UC, as UC and ED are part of the outputs of energy commitment.

- EC study provides more details and information about the grid than UC studies.

- UC focuses only on the operation of electrical energy demand, while the EC also considers other energy carriers.

- By implementing the EC on an energy grid, important outputs are obtained, including the need to differentiate energy carriers, ED and UC information, and the import and export of energy carriers.

- FOA algorithm has a good performance in solving the EC problem by presenting a smooth convergent curve and achieving the optimal solution in the appropriate number of iterations.

\section{Conclusions and Future Works}

Energy consumption is one of the criteria for determining the level of development and quality of life in a country. The continuity of energy supply and ensuring long-term access to resources have required a comprehensive energy plan. Energy carriers are one of the critical topics in the field of energy operation. Thus, this paper presents a methodology called Energy Commitment (EC) for the optimized operation of energy carriers using the Following Optimization Algorithm (FOA).

The goal in EC is determination of the most appropriate pattern of using energy carriers to supply energy demand considering technical and economic issues. EC is a constrained optimization problem that can be solved using various methods, especially the optimization algorithms. In this paper, the FOA algorithm has been applied to solve the EC problem. 
EC has been implemented on an energy grid with 10 power plants and including different consumption sectors of transportation, agriculture, industrial, residential, commercial, and general. Important outputs and information have been obtained by the implementation of an EC study on this energy network. This information and output signify the need for different energy carriers to meet the energy demand, the optimal combination and production of units (UC and EC outputs), and the amount of imports and exports of energy carriers.

Various combinations of power plants are available to supply the electricity demand for every hour of operation. According to the different fuel inputs to each power plant, different combinations of energy carriers are obtained. The appropriate combination of power plants and proper energy combination carriers to supply the energy consumption has been determined using the FOA. The FOA has a good performance in solving the EC problem by presenting a smooth convergent curve and achieving the optimal solution in the appropriate number of iterations.

The simulation results of the proposed study on the energy grid show that the EC analyzes the energy grid more efficiently and accurately than the UC. UC only studies the electrical energy network, while the EC operates energy carriers in an integrated energy network with energy demand for different energy carriers. Therefore, UC is one of the important outputs of the EC study and in fact, $\mathrm{UC}$ is a subset of the EC study.

The authors suggest implementing EC on various energy networks and scenarios, as well as using other optimization techniques for future studies. Ideas for further studies and future research include the introduction of new objective functions with new constraints such as the impact of $\mathrm{CO}_{2}$ and EC solving considering the response time required by each energy storage/carrier.

Author Contributions: Conceptualization, M.D., M.M., R.A.R.-M., R.M.-M., A.A. and J.M.G.; methodology, M.D.; software, M.D.; validation, J.M.G., J.M., R.A.R.-M., R.M.-M., A.A. and O.P.M.; formal analysis, R.M.-M., O.P.M.; investigation, M.D. and O.P.M.; resources, J.M.G.; data curation, A.A.; writing-original draft preparation, M.D. and M.M.; writing—review and editing, O.P.M., R.A.R.-M., R.M.-M., A.A. and J.M.G.; visualization, M.D.; supervision, M.M.; project administration, M.D. and M.M.; funding acquisition, R.A.R.-M., R.M.-M. All authors have read and agreed to the published version of the manuscript.

Funding: The current project was funded by Tecnológico de Monterrey and FEMSA Foundation (grant CAMPUSCITY project).

Conflicts of Interest: The authors declare no conflict of interest. The authors declare that they have no known competing financial interests or personal relationships that could have appeared to influence the work reported in this paper.

\section{Nomenclature}

$\begin{array}{ll}\text { EC } & \text { Energy Commitment } \\ \text { ED } & \text { Economic Dispatch } \\ \text { UC } & \text { Unit Commitment } \\ \text { MCE } & \text { Multi-Carrier Energy } \\ E H & \text { Energy Hub } \\ \text { MBOE } & \text { Millions of Barrels of Oil Equivalent } \\ E C_{f} & \text { Total energy demand } \\ E C_{i} & \text { Energy demand of the } i \text {-th sector } \\ N & \text { Number of different sectors } \\ E_{1} & \text { Energy demand matrix in the various energy sectors } \\ E C_{1} & \text { Total energy demand in residential, commercial, and public sector } \\ E C_{2} & \text { Total energy demand in industrial sector } \\ E C_{3} & \text { Total energy demand in transportation sector } \\ E C_{4} & \text { Total energy demand in agriculture sector } \\ E C_{5} & \text { Total energy demand in other sector } \\ E C_{6} & \text { Total energy demand in non }- \text { energy sector } \\ E_{2} & \text { Final energy consumption based on different energy carriers } \\ T_{1,2} & \text { The transform matrix of different sectors to different energy carriers }\end{array}$


$E_{3} \quad$ Final energy consumption based on different energy carriers considering losses

$T_{2,3} \quad$ Efficiency matrix

$E_{u} \quad$ Electrical energy of different power plants

$T_{u} \quad$ Separation matrix of electricity generated by various power plants

$E_{e} \quad$ Total electricity demand

$E_{e_{1}} \quad$ Input fuel for different power plant

$T_{u, f} \quad$ Power plant efficiency matrix

$E_{\ell_{2}} \quad$ Source energy carrier for electricity generation

$T_{f, c} \quad$ Conversion matrix of input fuel to energy carriers

$E_{4} \quad$ Final energy consumption after converting electrical energy to input carriers to units

$E_{p_{1}} \quad$ Energy carriers produced by refining

$T_{p} \quad$ Separation matrix of products created from refining crude oil

$E_{p} \quad$ Maximum capacity of refineries

$E_{5} \quad$ Final energy consumption after refining crude oil

$E_{6} \quad$ Import and/or export of energy carriers

$\mathrm{P} \quad$ Domestic production of energy carriers

$x_{i, 0}^{d} \quad$ Initial balance point along with the $d$ dimension of member $i$

$\mathrm{r} \quad$ Random number with a uniform distribution within [0,1] span

$x_{\text {leader }} \quad$ Best values of variables

f 'Following' co-efficient

$\mathrm{t} \quad$ Iteration count

$\mathrm{T} \quad$ Maximum number of iterations

fit Community fitness vector

$N_{c} \quad$ Number of various carriers

carrier $_{i}^{t} \quad$ Need to $i$-th carrier in $t$-th hour

price $_{i} \quad$ Price of $i$-th carrier

$N_{g} \quad$ Number of units

$S C_{i}^{t} \quad$ Start-up cost for $i$-th unit in $t$-th hour

$C_{i} \quad$ Fixed cost for $\mathrm{i}$-th unit

$u_{i}^{t} \quad$ Status (on or off) of $i$-th unit in $t$-th hour

$P_{g_{i}} \quad$ Production of $i$-th unit

load $\quad$ Electricity demand in $t$-th hour

\section{Appendix A}

Table A1. Unit Information.

\begin{tabular}{|c|c|c|c|c|c|c|}
\hline \multirow{2}{*}{ Row } & \multirow{2}{*}{ Power Plant } & \multicolumn{2}{|c|}{ The Capacity of the Unit (MW) } & \multirow{2}{*}{ Efficiency } & \multirow{2}{*}{ Constant Cost } & \multirow{2}{*}{ Priority } \\
\hline & & Min & Max & & & \\
\hline 1 & Thermal & 150 & 455 & 0.368 & 1 & 1 \\
\hline 2 & Thermal & 150 & 455 & 0.345 & 2 & 2 \\
\hline 3 & Combined Cycle & 20 & 130 & 0.455 & 3 & 3 \\
\hline 4 & Thermal & 20 & 130 & 0.317 & 4 & 4 \\
\hline 5 & Gas & 25 & 162 & 0.3 & 5 & 5 \\
\hline 6 & Combined Cycle & 20 & 80 & 0.47 & 6 & 6 \\
\hline 7 & Thermal & 25 & 85 & 0.35 & 7 & 7 \\
\hline 8 & Thermal & 10 & 55 & 0.35 & 8 & 8 \\
\hline 9 & Combined Cycle & 10 & 55 & 0.5 & 9 & 9 \\
\hline 10 & Gas & 10 & 55 & 0.25 & 10 & 10 \\
\hline
\end{tabular}


Table A2. The time information of units.

\begin{tabular}{cccccc}
\hline Row & Power Plant & MUT & MDT & Cold Start & Initial Conditions \\
\hline 1 & Thermal & 8 & 8 & 5 & 8 \\
2 & Thermal & 8 & 8 & 5 & 8 \\
3 & Combined Cycle & 5 & 5 & 4 & -5 \\
4 & Thermal & 5 & 5 & 4 & -5 \\
5 & Gas & 6 & 6 & 4 & -6 \\
6 & Combined Cycle & 3 & 3 & 2 & -3 \\
7 & Thermal & 3 & 3 & 2 & -3 \\
8 & Thermal & 1 & 1 & 0 & -1 \\
9 & Combined Cycle & 1 & 1 & 0 & -1 \\
10 & Gas & 1 & 1 & 0 & -1 \\
\hline
\end{tabular}

Table A3. Startup cost (US dollar).

\begin{tabular}{cccc}
\hline Row & Power Plant & Hot start & Cold Start \\
\hline 1 & Thermal unit & 4500 & 9000 \\
2 & Thermal unit & 5000 & 10,000 \\
3 & Combined Cycle unit & 550 & 1100 \\
4 & Thermal unit & 560 & 1120 \\
5 & Gas unit & 900 & 1800 \\
6 & Combined Cycle unit & 170 & 340 \\
7 & Thermal unit & 260 & 520 \\
8 & Thermal unit & 30 & 60 \\
9 & Combined Cycle unit & 30 & 60 \\
10 & Gas unit & 30 & 60 \\
\hline
\end{tabular}

Table A4. Matrix $T_{p}$.

\begin{tabular}{lc}
\hline Petroleum & 0 \\
\hline liquid gas & 0.032 \\
Fuel oil & 0.293 \\
Gas oil & 0.293 \\
Kerosene & 0.099 \\
Gasoline & 0.157 \\
plane fuel & 0 \\
Other products & 0.058 \\
natural gas & 0 \\
Coke gas & 0 \\
Coal & 0 \\
Non-commercial fuels & 0 \\
Electricity(power) & 0 \\
\hline
\end{tabular}

Table A5. Conversion matrix input energy to fuel power plants.

\begin{tabular}{cccc}
\hline Power Plant & Thermal Unit & Combined Cycle Unit & Gas Unit \\
\hline Fuel oil & 0.254 & 0 & 0 \\
Gas oil & 0.003 & 0.082 & 0.166 \\
natural gas & 0.743 & 0.918 & 0.834 \\
\hline
\end{tabular}


Table A6. Domestic supplies of energy carriers.

\begin{tabular}{ccc}
\hline Row & Energy Carrier & Energy (boe) \\
\hline 1 & Petroleum & 11,086 \\
2 & liquid gas & 0 \\
3 & Fuel oil & 0 \\
4 & Gas oil & 0 \\
5 & Kerosene & 0 \\
6 & Gasoline & 0 \\
7 & plane fuel & 0 \\
8 & Other products & 0 \\
9 & natural gas & 42,461 \\
10 & Coke gas & 28.0532 \\
11 & Coal & 42.0799 \\
12 & Non-commercial fuels & 169.6553 \\
13 & Electricity(power) & 0 \\
\hline
\end{tabular}

Table A7. Heating value [47] and energy rates [48].

\begin{tabular}{ccc}
\hline Energy Carrier & Heating Value & Energy Rates \\
\hline Petroleum & $38.5 \frac{\mathrm{MJ}}{\mathrm{Lit}}$ & 48 dollar/boe \\
liquid gas & $46.15 \frac{\mathrm{MJ}}{\mathrm{Kg}}$ & 374 dollar/tone \\
Fuel oil & $42.18 \frac{\mathrm{MJ}}{\mathrm{Kg}}$ & 180 dollar/tone \\
Gas oil & $43.38 \frac{\mathrm{MJ}}{\mathrm{Kg}}$ & 350 dollar/tone \\
Kerosene & $43.32 \frac{\mathrm{MJ}}{\mathrm{Kg}}$ & 500 dollar/tone \\
Gasoline & $44.75 \frac{\mathrm{MJ}}{\mathrm{Kg}}$ & 450 dollar/tone \\
plane fuel & $45.03 \frac{\mathrm{MJ}}{\mathrm{Kg}}$ & 555 dollar/tone \\
natural gas & $39 \frac{\mathrm{MJ}}{\mathrm{m}}$ & 237 dollar/1e3m \\
Coke gas & $16.9 \frac{\mathrm{MJ}}{\mathrm{Kg}}$ & 157 dollar/tone \\
coal & $26.75 \frac{\mathrm{MJ}}{\mathrm{Kg}}$ & 61 dollar/tone \\
\hline
\end{tabular}


Table A8. Final energy consumption (BOE).

\begin{tabular}{|c|c|c|c|c|c|c|c|c|}
\hline Hour & 1 & 2 & 3 & 4 & 5 & 6 & 7 & 8 \\
\hline $\begin{array}{c}\text { Residential, } \\
\text { commercial, and } \\
\text { public }\end{array}$ & 1640.43 & 1757.603 & 1991.95 & 2226 & 234 & 2577.818 & 2694.992 & 2812.165 \\
\hline Industrial & 772.0152 & 827.1591 & 937.447 & 1047.735 & 1102.879 & 1213.167 & 1268.311 & 1323.455 \\
\hline Transportation & 1043.164 & 1117.676 & 1266.699 & 1415.723 & 1490.234 & 1639.258 & 1713.769 & 1788.281 \\
\hline Agriculture & 137.0101 & 146.7966 & 166.3694 & 185.9423 & 195.7288 & 215.3016 & 225.0881 & 234.8745 \\
\hline Other & 10.25525 & 10.98777 & 12.4528 & 13.91784 & 14.65036 & 16.11539 & 16.84791 & 17.58043 \\
\hline Non-energy & 349.9091 & 374.9026 & 424.8896 & 474.8766 & 499.8702 & 549.8572 & 574.8507 & 599.8442 \\
\hline Hour & 9 & 10 & 11 & 12 & 13 & 14 & 15 & 16 \\
\hline $\begin{array}{c}\text { Residential, } \\
\text { commercial, and } \\
\text { public }\end{array}$ & 3046.512 & 3398.033 & 3632.38 & 3878.444 & 3515.206 & 3280.859 & 2812.165 & 2460.645 \\
\hline Industrial & 1433.742 & 1599.174 & 1709.462 & 1825.264 & 1654.318 & 1544.03 & 1323.455 & 1158.023 \\
\hline Transportation & 1937.305 & 2160.84 & 2309.863 & 2466.338 & 2235.351 & 2086.328 & 1788.281 & 1564.746 \\
\hline Agriculture & 254.4474 & 283.8067 & 303.3796 & 323.9311 & 293.5931 & 274.0203 & 234.8745 & 205.5152 \\
\hline Other & 19.04546 & 21.24302 & 22.70805 & 24.24634 & 21.97553 & 20.5105 & 17.58043 & 15.38287 \\
\hline Non-energy & 649.8312 & 724.8117 & 774.7987 & 827.2851 & 749.8052 & 699.8182 & 599.8442 & 524.8637 \\
\hline Hour & 17 & 18 & 19 & 20 & 21 & 22 & 23 & 24 \\
\hline $\begin{array}{c}\text { Residential, } \\
\text { commercial, and } \\
\text { public }\end{array}$ & 2343.471 & 2812.165 & 3280.859 & 3046.512 & 2577.818 & 2109.124 & 1991.95 & 1874.777 \\
\hline Industrial & 1102.879 & 1323.455 & 1544.03 & 1433.742 & 1213.167 & 992.5909 & 937.447 & 882.3031 \\
\hline Transportation & 1490.234 & 1788.281 & 2086.328 & 1937.305 & 1639.258 & 1341.211 & 1266.699 & 1192.187 \\
\hline Agriculture & 195.7288 & 234.8745 & 274.0203 & 254.4474 & 215.3016 & 176.1559 & 166.3694 & 156.583 \\
\hline Other & 14.65036 & 17.58043 & 20.5105 & 19.04546 & 16.11539 & 13.18532 & 12.4528 & 11.72028 \\
\hline Non-energy & 499.8702 & 599.8442 & 699.8182 & 649.8312 & 549.8572 & 449.8831 & 424.8896 & 399.8961 \\
\hline
\end{tabular}

Table A9. $T_{1,2}$ Matrix.

\begin{tabular}{ccccccc}
\hline & $\begin{array}{c}\text { Residential, } \\
\text { Commercial and } \\
\text { Public }\end{array}$ & Industrial & Transportatior & Agriculture & Other & Non-Energy \\
\hline Petroleum & 0 & 0 & 0 & 0 & 0 & 0 \\
Liquid gas & 0.051 & 0.013 & 0.01 & 0 & 0 & 0 \\
Fuel oil & 0.023 & 0.212 & 0.014 & 0 & 0 & 0 \\
Gas oil & 0.055 & 0.087 & 0.363 & 0.689 & 0 & 0 \\
Kerosene & 0.141 & 0.002 & 0 & 0.018 & 0 & 0 \\
Gasoline & 0.002 & 0.002 & 0.573 & 0.003 & 0 & 0 \\
Plane fuel & 0 & 0 & 0.031 & 0 & 0 & 0 \\
Other products & 0 & 0 & 0 & 0 & 0 & 0.402 \\
Natural gas & 0.564 & 0.521 & 0.007 & 0 & 0 & 0.497 \\
Coke gas & 0 & 0.021 & 0 & 0 & 0 & 0 \\
Coal & 0.0003 & 0 & 0 & 0 & 0 & 0.101 \\
Non-commercial fuels & 0.064 & 0 & 0 & 0 & 0 & 0 \\
Electricity (power) & 0.102 & 0.142 & 0.0004 & 0.29 & 1 & 0 \\
\hline
\end{tabular}


Table A10. Matrix $\mathrm{T}_{23}$.

\begin{tabular}{|c|c|c|c|c|c|c|c|c|c|c|c|c|c|}
\hline Petroleum & 1 & 0 & 0 & 0 & 0 & 0 & 0 & 0 & 0 & 0 & 0 & 0 & 0 \\
\hline Liquid gas & 0 & 1 & 0 & 0 & 0 & 0 & 0 & 0 & 0 & 0 & 0 & 0 & 0 \\
\hline Fuel oil & 0 & 0 & 1 & 0 & 0 & 0 & 0 & 0 & 0 & 0 & 0 & 0 & 0 \\
\hline Gas oil & 0 & 0 & 0 & 1 & 0 & 0 & 0 & 0 & 0 & 0 & 0 & 0 & 0 \\
\hline Kerosene & 0 & 0 & 0 & 0 & 1 & 0 & 0 & 0 & 0 & 0 & 0 & 0 & 0 \\
\hline Gasoline & 0 & 0 & 0 & 0 & 0 & 1 & 0 & 0 & 0 & 0 & 0 & 0 & 0 \\
\hline Plane fuel & 0 & 0 & 0 & 0 & 0 & 0 & 1 & 0 & 0 & 0 & 0 & 0 & 0 \\
\hline Other products & 0 & 0 & 0 & 0 & 0 & 0 & 0 & 1 & 0 & 0 & 0 & 0 & 0 \\
\hline Natural gas & 0 & 0 & 0 & 0 & 0 & 0 & 0 & 0 & 1.1601 & 0 & 0 & 0 & 0 \\
\hline Coke gas & 0 & 0 & 0 & 0 & 0 & 0 & 0 & 0 & 0 & 1 & 0 & 0 & 0 \\
\hline Coal & 0 & 0 & 0 & 0 & 0 & 0 & 0 & 0 & 0 & 0 & 1 & 0 & 0 \\
\hline Non-commercial fuels & 0 & 0 & 0 & 0 & 0 & 0 & 0 & 0 & 0 & 0 & 0 & 1 & 0 \\
\hline Electricity (power) & 0 & 0 & 0 & 0 & 0 & 0 & 0 & 0 & 0 & 0 & 0 & 0 & 1.3158 \\
\hline
\end{tabular}

\section{References}

1. Montazeri, Z.; Niknam, T. Optimal Utilization of Electrical Energy from Power Plants Based on Final Energy Consumption Using Gravitational Search Algorithm. Електротехніка Електромеханіка 2018, 4, 70-73. [CrossRef]

2. Babaei, S.; Zhao, C.; Fan, L. A Data-Driven Model of Virtual Power Plants in Day-Ahead Unit Commitment. IEEE Trans. Power Syst. 2019, 34, 5125-5135. [CrossRef]

3. Xavier, A.S.; Qiu, F.; Wang, F.; Thimmapuram, P.R. Transmission Constraint Filtering in Large-Scale Security-Constrained Unit Commitment. IEEE Trans. Power Syst. 2019, 34, 2457-2460. [CrossRef]

4. Luburić, Z.; Pandžić, H. FACTS Devices and Energy Storage in Unit Commitment. Int. J. Electrical. Power Energy Syst. 2019, 104, 311-325. [CrossRef]

5. Mitani, T.; Aziz, M.; Oda, T.; Uetsuji, A.; Watanabe, Y.; Kashiwagi, T. Annual assessment of large-scale introduction of renewable energy: Modeling of unit commitment schedule for thermal power generators and pumped storages. Energies 2017, 10, 738. [CrossRef]

6. Suazo-Martínez, C.; Pereira-Bonvallet, E.; Palma-Behnke, R. A simulation framework for optimal energy storage sizing. Energies 2014, 7, 3033-3055. [CrossRef]

7. Ju, Y.; Wang, J.; Ge, F.; Lin, Y.; Dong, M.; Li, D.; Shi, K.; Zhang, H. Unit Commitment Accommodating Large Scale Green Power. Appl. Sci. 2019, 9, 1611. [CrossRef]

8. Ting, T.; Rao, M.; Loo, C. A Novel Approach for Unit Commitment Problem via an Effective Hybrid Particle Swarm Optimization. IEEE Trans. Power Syst. 2006, 21, 411-418. [CrossRef]

9. Nemati, M.; Braun, M.; Tenbohlen, S. Optimization of Unit Commitment and Economic Dispatch in Microgrids Based on Genetic Algorithm and Mixed Integer Linear Programming. Appl. Energy 2018, 210, 944-963. [CrossRef]

10. Panwar, L.K.; Reddy, S.; Verma, A.; Panigrahi, B.K.; Kumar, R. Binary Grey Wolf Optimizer for Large Scale Unit Commitment Problem. Swarm Evol. Comput. 2018, 38, 251-266. [CrossRef]

11. Reddy, K.S.; Panwar, L.; Panigrahi, B.; Kumar, R. Binary Whale Optimization Algorithm: A New Metaheuristic Approach for Profit-Based Unit Commitment Problems in Competitive Electricity Markets. Eng. Optim. 2019, 51, 369-389. [CrossRef]

12. Simopoulos, D.N.; Kavatza, S.D.; Vournas, C.D. Reliability Constrained Unit Commitment Using Simulated Annealing. IEEE Trans. Power Syst. 2006, 21, 1699-1706. [CrossRef]

13. Ebrahimi, J.; Hosseinian, S.H.; Gharehpetian, G.B. Unit Commitment Problem Solution Using Shuffled Frog Leaping Algorithm. IEEE Trans. Power Syst. 2011, 26, 573-581. [CrossRef]

14. Geidl, M.; Andersson, G. Optimal Power Flow of Multiple Energy Carriers. IEEE Trans. Power Syst. 2007, 22, 145-155. [CrossRef]

15. Solanki, B.V.; Raghurajan, A.; Bhattacharya, K.; Cañizares, C.A. Including Smart Loads for Optimal Demand Response in Integrated Energy Management Systems for Isolated Microgrids. IEEE Trans. Smart Grid 2015, 8, 1739-1748. [CrossRef]

16. Pazouki, S.; Haghifam, M.-R. Comparison between Demand Response Programs in Multiple Carrier Energy Infrastructures in Presence of Wind and Energy Storage Technologies. In Proceedings of the 2014 Smart Grid Conf (SGC), Tehran, Iran, 9-10 December 2014; pp. 1-6. 
17. Shabanpour-Haghighi, A.; Seifi, A.R.; Niknam, T. A Modified Teaching-Learning Based Optimization for Multi-Objective Optimal Power Flow Problem. Energy Convers. Manag. 2014, 77, 597-607. [CrossRef]

18. Sadeghi, H.; Rashidinejad, M.; Moeini-Aghtaie, M.; Abdollahi, A. The Energy Hub: An Extensive Survey on the State-of-the-Art. Appl. Therm. Eng. 2019, 161, 114071. [CrossRef]

19. Biglia, A.; Caredda, F.V.; Fabrizio, E.; Filippi, M.; Mandas, N. Technical-Economic Feasibility of CHP Systems in Large Hospitals through the Energy Hub Method: The Case of Cagliari AOB. Energy Build. 2017, 147, 101-112. [CrossRef]

20. Ma, T.; Wu, J.; Hao, L. Energy Flow Modeling and Optimal Operation Analysis of the Micro Energy Grid Based on Energy HUB. Energy Convers. Manag. 2017, 133, 292-306. [CrossRef]

21. Huo, D.; Le Blond, S.; Gu, C.; Wei, W.; Yu, D. Optimal Operation of Interconnected Energy Hubs by Using Decomposed Hybrid Particle Swarm and Interior-Point Approach. Int. J. Electr. Power Energy Syst. 2018, 95, 36-46. [CrossRef]

22. Asl, D.K.; Hamedi, A.; Seifi, A.R. Planning, Operation and Flexibility Contribution of Multi-Carrier Energy Storage Systems in Integrated Energy Systems. IET Renew. Power Gener. 2019, 14, 408-416.

23. Shahmohammadi, A.; Moradi-Dalvand, M.; Ghasemi, H.; Ghazizadeh, M. Optimal Design of Multicarrier Energy Systems Considering Reliability Constraints. IEEE Trans. Power Deliv. 2014, 30, 878-886. [CrossRef]

24. Sheikhi, A.; Bahrami, S.; Ranjbar, A.M. An Autonomous Demand Response Program for Electricity and Natural Gas Networks in Smart Energy HUBs. Energy 2015, 89, 490-499. [CrossRef]

25. Li, J.; Niu, D.; Wu, M.; Wang, Y.; Li, F.; Dong, H. Research on Battery Energy Storage as Backup Power in the Operation Optimization of a Regional Integrated Energy System. Energies 2018, 11, 2990. [CrossRef]

26. Huang, Y.; Yang, K.; Zhang, W.; Lee, K.Y. Hierarchical Energy Management for the Multienergy Carriers System with Different Interest Bodies. Energies 2018, 11, 2834. [CrossRef]

27. Hazem Mohammed, O.; Amirat, Y.; Benbouzid, M. Economical Evaluation and Optimal Energy Management of a Stand-Alone Hybrid Energy System Handling in Genetic Algorithm Strategies. Electronics 2018, 7, 233. [CrossRef]

28. Veras, J.M.; Silva, I.R.S.; Pinheiro, P.R.; Rabêlo, R.A.L.; Veloso, A.F.S.; Borges, F.A.S.; Rodrigues, J.J.P.C. A Multi-Objective Demand Response Optimization Model for Scheduling Loads in a Home Energy Management System. Sensors 2018, 18, 3207. [CrossRef]

29. Jiang, T.; Zhang, C.; Zhu, H.; Gu, J.; Deng, G. Energy-Efficient Scheduling for a Job Shop Using an Improved Whale Optimization Algorithm. Mathematics 2018, 6, 220. [CrossRef]

30. IEA. Energy Statistics Manual; OECD Publishing: Paris, France, 2004.

31. Dehghani, M.; Montazeri, Z.; Dehghani, A.; Seifi, A. Spring Search Algorithm: A New Meta-Heuristic Optimization Algorithm Inspired by Hooke's Law. In Proceedings of the 2017 IEEE 4th International Conference on Knowledge-Based Engineering and Innovation (KBEI), Tehran, Iran, 22 December 2017; pp. 0210-0214.

32. Dehghani, M.; Montazeri, Z.; Dehghani, A.; Nouri, N.; Seifi, A. BSSA: Binary Spring Search Algorithm. In Proceedings of the 2017 IEEE 4th International Conference on Knowledge-Based Engineering and Innovation (KBEI), Tehran, Iran, 22 December 2017; pp. 0220-0224.

33. Dehghani, M.; Montazeri, Z.; Malik, O.P.; Ehsanifar, A.; Dehghani, A. OSA: Orientation Search Algorithm. Int. J. Ind. Electron. Control Optim. 2019, 2, 99-112.

34. Dehghani, M.; Montazeri, Z.; Malik, O.P.; Dhiman, G.; Kumar, V. BOSA: Binary Orientation Search Algorithm. Int. J. Innov. Technol. Explor. Eng. (IJITEE) 2019, 9, 5306-5310.

35. Dehghani, M.; Montazeri, Z.; Malik, O.P. DGO: Dice Game Optimizer. Gazi Univ. J. Sci. 2019, 32, 871-882. [CrossRef]

36. Dehghani, M.; Montazeri, Z.; Dehghani, A.; Malik, O.P. GO: Group Optimization. Gazi Univ. J. Sci. 2020, 33, 381-392. [CrossRef]

37. Mohammad, D.; Zeinab, M.; Malik, O.P.; Givi, H.; Guerrero, J.M. Shell Game Optimization: A Novel Game-Based Algorithm. Int. J. Intell. Eng. Syst. 2020, 13, 10.

38. Dehghani, M.; Montazeri, Z.; Saremi, S.; Dehghani, A.; Malik, O.P.; Al-Haddad, K.; Guerrero, J.M. HOGO: Hide Objects Game Optimization. Int. J. Intell. Eng. Syst. 2020, 13, 10.

39. Dehghani, M.; Mardaneh, M.; Malik, O.P.; NouraeiPour, S.M. DTO: Donkey Theorem Optimization. In Proceedings of the 2019 27th Iranian Conference on Electrical Engineering (ICEE), Yazd, Iran, 30 April-2 May 2019; pp. 1855-1859. 
40. Dhiman, G.; Garg, M.; Nagar, A.K.; Kumar, V.; Dehghani, M. A Novel Algorithm for Global Optimization: Rat Swarm Optimizer. J. Ambient Intell. Humaniz. Comput. 2020. Available online: https://hira.hope.ac.uk/id/ eprint/3100/ (accessed on 12 August 2020).

41. Dehghani, M.; Montazeri, Z.; Malik, O. Energy Commitment: A Planning of Energy Carrier Based on Energy Consumption. Электротехника Электромеханика 2019, 4, 69-72. [CrossRef]

42. Ehsanifar, A.; Dehghani, M.; Allahbakhshi, M. Calculating The Leakage Inductance for Transformer Inter-Turn Fault Detection Using Finite Element Method. In Proceedings of the 2017 Iranian Conference on Electrical Engineering (ICEE), Tehran, Iran, 2-4 May 2017; pp. 1372-1377.

43. Dehghani, M.; Montazeri, Z.; Malik, O. Optimal Sizing and Placement of Capacitor Banks and Distributed Generation in Distribution Systems Using Spring Search Algorithm. Int. J. Emerg. Electr. Power Syst. 2020, 21, 1-7. [CrossRef]

44. Dehghani, M.; Montazeri, Z.; Malik, O.P.; Al-Haddad, K.; Guerrero, J.M.; Dhiman, G. A New Methodology Called Dice Game Optimizer for Capacitor Placement in Distribution Systems. Электротехника Электромеханика 2020, 1, 61-64. [CrossRef]

45. Dehbozorgi, S.; Ehsanifar, A.; Montazeri, Z.; Dehghani, M.; Seifi, A. Line Loss Reduction and Voltage Profile Improvement in Radial Distribution Networks Using Battery Energy Storage System. In Proceedings of the 2017 IEEE 4th International Conference on Knowledge-Based Engineering and Innovation (KBEI), Tehran, Iran, 22 December 2017; pp. 0215-0219.

46. Dehghani, M.; Mardaneh, M.; Montazeri, Z.; Ehsanifar, A.; Ebadi, M.; Grechko, O. Spring Search Algorithm for Simultaneous Placement of Distributed Generation and Capacitors. Электротехника Иэлектромеханика 2018, 6, 68-73. [CrossRef]

47. Dehghani, M.; Montazeri, Z.; Ehsanifar, A.; Seifi, A.; Ebadi, M.; Grechko, O. Planning of Energy Carriers Based on Final Energy Consumption Using Dynamic Programming and Particle Swarm Optimization. Электротехника Электромеханика 2018, 5, 62-71. [CrossRef]

48. Montazeri, Z.; Niknam, T. Energy Carriers Management Based on Energy Consumption. In Proceedings of the 2017 IEEE 4th International Conference on Knowledge-Based Engineering and Innovation (KBEI), Tehran, Iran, 22 December 2017; pp. 0539-0543.

49. Dehghani, M.; Mardaneh, M.; Malik, O. FOA: Following Optimization Algorithm for Solving Power Engineering Optimization Problems. J. Oper. Autom. Power Eng. 2020, 8, 57-64. 